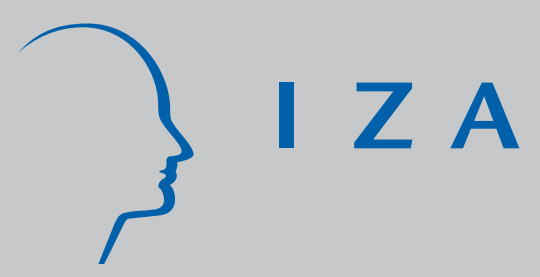

IZADP No. 3571

The Nature of Occupational Unemployment Rates in the United States: Hysteresis or Structural?

\author{
Bertrand Candelon \\ Arnaud Dupuy \\ Luis Gil-Alana \\ J une 2008
}




\title{
The Nature of Occupational Unemployment Rates in the United States: Hysteresis or Structural?
}

\author{
Bertrand Candelon \\ Maastricht University \\ Arnaud Dupuy \\ ROA, Maastricht University \\ Luis Gil-Alana \\ University of Navarre
}
Discussion Paper No. 3571
June 2008

IZA
P.O. Box 7240
53072 Bonn
Germany

Phone: +49-228-3894-0

Fax: +49-228-3894-180

E-mail: iza@iza.org

\begin{abstract}
Any opinions expressed here are those of the author(s) and not those of IZA. Research published in this series may include views on policy, but the institute itself takes no institutional policy positions.

The Institute for the Study of Labor (IZA) in Bonn is a local and virtual international research center and a place of communication between science, politics and business. IZA is an independent nonprofit organization supported by Deutsche Post World Net. The center is associated with the University of Bonn and offers a stimulating research environment through its international network, workshops and conferences, data service, project support, research visits and doctoral program. IZA engages in (i) original and internationally competitive research in all fields of labor economics, (ii) development of policy concepts, and (iii) dissemination of research results and concepts to the interested public.
\end{abstract}

IZA Discussion Papers often represent preliminary work and are circulated to encourage discussion. Citation of such a paper should account for its provisional character. A revised version may be available directly from the author. 


\section{ABSTRACT \\ The Nature of Occupational Unemployment Rates in the United States: Hysteresis or Structural?*}

This paper provides new evidence on the nature of occupational differences in unemployment dynamics, which is relevant for the debate between the structural or hysteresis hypotheses. We develop a procedure that permits us to test for the presence of a structural break at unknown date. Our approach allows the investigation of a broader range of persistence than the 0/1 paradigm about the order of integration, usually implemented for testing the hypothesis of hysteresis in occupational unemployment. In almost all occupations, we find support for both the structuralist and the hysteresis hypotheses, but stress the importance of estimating the degree of persistence of seasonal shocks along with the degree of long-run persistence on raw data without applying seasonal filters. Indeed hysteresis appears to be underestimated when data are initially adjusted using traditional seasonal filters.

JEL Classification: E24, C22, J62

Keywords: $\quad$ occupational unemployment, structuralist, hysteresis, structural break, fractional integration

Corresponding author:

Arnaud Dupuy

ROA, Maastricht University

P.O. Box 616

NL-6200 MD Maastricht

The Netherlands

E-mail: a.dupuy@roa.unimaas.nl

\footnotetext{
* We thank participants at a seminar at Maastricht University. Luis Gil-Alana thanks the financial support from the Ministerio de Ciencia y Tecnologia (SEJ2005-07657/ECON, Spain).
} 


\section{Introduction}

Unemployment rates vary greatly across occupations and persistent higher unemployment rates are observed in low skill jobs. Starting with Thurow (1965), (see also Ray (1976) and Devereux (2002) for instance) empirical studies have acknowledged structural differences in patterns of unemployment across occupations. ${ }^{1}$ The main result put forward in these studies is that although aggregate unemployment is counter cyclical as predicted by Okun's law, ${ }^{2}$ the magnitude of the cyclical effects on unemployment is greater in low skill jobs and blue-collar occupations. As a result, occupational unemployment tends to converge in periods of expansion and diverge during periods of recession. An explanation often put forward for this cyclical pattern is that low skilled labor is associated with lower hiring and firing costs.

So far, empirical studies investigating occupational differences in unemployment have adopted the traditional structural approach developed by Phelps $(1967 ; 1968)$ and Friedman (1968), which describes cyclical fluctuations in occupational unemployment as movements, of amplitude specific to each occupation, around a common natural rate of unemployment, i.e. what is usually called "the law of one natural rate of unemployment." However, the traditional theory has been challenged by the persistence of high unemployment rates in European countries for 30 years and is furthermore challenged in the context of occupational unemployment by the persistently higher unemployment rates, which are observed in low skill jobs. The persistence of high unemployment has led to the development of two new competing theories. The hysteresis theory, advanced by Blanchard and Summers $(1986 ; 1987)$ and Cross $(1987)$, argues that temporary shocks have permanent or very persistent effects on the unemployment rate. According to this theory, the unemployment rate is a stochastic process with long memory, exhibiting hence a (near) unit root. In contrast, the structuralist theory advanced by Phelps (1994) consists of "endogenizing" the natural rate of unemployment. In the struc-

\footnotetext{
${ }^{1}$ Other studies have focused on demographic differences (Clark and Summers (1981), Vedder and Gallaway (1992) and Tolvi (2003) among others) and differences between skill groups ( Teulings and Koopmanschrap (1989) and Fabiani et al. (2001) among others). These studies indicate that minorities and less skilled workers have experienced persistently higher unemployment rates and greater cyclical variations.

${ }^{2}$ See Okun (1962).
} 
turalist theory, as in the traditional theory, fluctuations in unemployment are viewed as movements around the natural rate of unemployment. However, in the structuralist theory, the natural rate of unemployment is considered as being subject to structural breaks caused by changes in the structural factors of the economy. This theory thus contends that the unemployment rate is a stationary process subject to occasional but persistent structural changes.

The aim of this paper is to provide new evidence on the nature of occupational differences in unemployment patterns. We contribute to the unemployment literature in two ways:

i) We first disaggregate unemployment series by occupation in order to isolate skill-specific patterns in unemployment. ii) We depart from the traditional structural approach by considering both Phelps's (1994) structural theory and Blanchard and Summers's (1986) hysteresis theory as potential candidates in explaining persistent differences in occupational unemployment patterns. The structural explanation of persistently higher unemployment rates observed in low skill jobs is that each occupation has a different natural rate of unemployment subject to occasional, but persistent, structural breaks that have a larger magnitude in low skill jobs. The hysteresis explanation is that macroeconomic shocks have a larger degree of persistence on unemployment in low skill occupations than in high skill ones.

Another contribution is econometric in nature. In contrast to previous studies on unemployment, we investigate the possibility that a specific structural break occurs in each occupation and possibly with a different unknown timing, considering that, in each occupation, shocks may also have different fractional degrees of persistence. To this aim, we develop a procedure for testing for the presence of a structural break at unknown date in a fractional integration framework. Previous tests for structural breaks in fractionally integrated series required the timing of the break to be known ex ante, see Gil-Alana (2002). Fractional integration allows us to investigate a broader range of persistence or memory than the $0 / 1$ paradigm most notably implemented in studies of unemployment patterns. Hysteresis stricto sensus is met when the degree of persistence is unity, where the unemployment rate has a permanent memory. However, series of unem- 
ployment rates could have a long though less than permanent memory, if the order of integration is strictly higher than 0 but smaller than 1 . For degrees of integration equal to 0 , the unemployment rate series are said to have short memory if they are autocorrelated (e.g. ARMA). Moreover, we distinguish the "traditional" or "long-run" hysteresis from the seasonal hysteresis. Macroeconomic time series like unemployment rates usually exhibit large seasonal fluctuations. The traditional approach to this issue has been to consider the seasonality in these series as non-informative (in an economic sense) and therefore use seasonally adjusted data for their analyses. However, recent empirical evidence shows that i) seasonality in macroeconomic series changes over time ${ }^{3}$ (van Dijk et al. (2003)), possibly interacts with the business cycle ${ }^{4}$ (see Ghysels (1994), Miron and Beaulieu (1996)) and may even trigger the business cycle as shown by Wen (2002), ii) introduces biases in traditional unit root tests (Hasza and Fuller (1982) and Candelon and Gil-Alana (2004)) and iii) inappropriate seasonal filters create a spurious regression problem (see Miron (1990) and Abeysinghe (1994)). These three points call for a careful investigation of the seasonal component in macroeconomic series.

The main findings of the paper can be summarized as follows: i) the structuralist hypothesis is supported as a structural break is found in the early $90 \mathrm{~s}$ in all our experiments, ii) the hysteresis hypothesis is also supported, as all series exhibit large degrees of fractional integration, indicating thus long memory and iii) our experiments stress the importance of estimating the degree of persistence of seasonal shocks along with the degree of long-run persistence on raw data without applying seasonal filters. In fact, hysteresis appears to be underestimated when data are adjusted using traditional seasonal filters.

The structure of the paper is as follows. In Section 2 we propose a review of the models used in the hysteresis/structuralist literature in order to model unemployment. In section 3 , the test for seasonal and long run fractional unit roots in the presence of a structural break at an unknown date is presented. Section 4 deals with the empirical application. Section 5 concludes.

\footnotetext{
${ }^{3}$ Although remarked long ago (see Gjermoe (1931) and Kuznets (1932)), it is only recently that economists have explicitly allowed seasonality to change over time.

${ }^{4}$ However, van Dijk et al. (2003) conclude that cyclical changes in seasonality are unimportant.
} 


\section{Background}

The first empirical studies to investigate patterns of unemployment adopted the traditional structural approach developed by Phelps $(1967 ; 1968)$ and Friedman (1968) and described cyclical fluctuations in unemployment as movements around a constant natural rate of unemployment. However, the traditional theory has been challenged by the persistence of high unemployment rates in European countries for 30 years. This persistence has led to the development of two new competing theories.

The hysteresis theory advanced by Blanchard and Summers $(1986 ; 1987)$ and Cross $(1987)$ argues that temporary shocks have very persistent if not permanent effects on the unemployment rate. Thus, the unemployment rate is a stochastic process with long memory and exhibits a (near) unit root. The first studies to investigate hysteresis in aggregate unemployment estimated ARIMA processes, see among others Blanchard and Summers (1986), Barro (1988), Alogoskoufis and Manning (1988) and Mitchell (1993). The unemployment rate, say $u_{t}$, is assumed to follow the following process:

$$
\Phi(L) u_{t}=\Psi(L) \epsilon_{t}
$$

where $L$ is the lag operator $\left(L u_{t}=u_{t-1}\right), \Phi(L)$ and $\Psi(L)$ are two polynomials of order $p$ and $q$ and $\epsilon_{t}$ is i.i.d. $\left(0, \sigma^{2}\right)$

Assuming invertibility of the MA polynomial $\Psi(L)$, the previous process can be written as:

$$
C(L) u_{t}=\epsilon_{t}
$$

with the roots of $C(L)$ lying outside the unit circle.

The above-mentioned studies then tested for the roots of $C(L)$ and provided evidence in favor of hysteresis (ARIMA) as they could not reject the null hypothesis of unit root. However, ARIMA analyses are bounded 
within the 0/1 paradigm: $u_{t}$ either possesses a unit root (integrated of order 1 ) or is stationary (more precisely, integrated of degree 0) and therefore only allow economists to test for short memory against shocks having permanent effects. Moreover, it is a well-known stylized fact that classic unit root testing procedures (Dickey and Fuller (1979), Phillips and Perron (1988)) have very low power if the alternatives are of fractional form (see, e.g. Diebold and Rudebush, 1991, Hassler and Wolters, 1994). Asides from this, the unit root tests are not robust to the presence of structural breaks at known or unknown break dates (see Andrews (1993)). This casts some doubt on the reliability of former results since structural shifts in the natural rate of unemployment could have led unit root tests to conclude in favor of hysteresis.

In contrast, the structuralist theory advanced by Phelps (1994) consists of "endogenizing" the natural rate of unemployment. In this theory, as in the traditional theory, fluctuations in unemployment are viewed as movements around the natural rate of unemployment. However, in opposition to the proponents of the traditional theory, the structuralists argue that the natural rate of unemployment is subject to structural breaks caused by changes in fundamental factors in the economy. Accordingly, the unemployment rate is a stationary process subject to occasional but persistent structural changes. Only recently, researchers have shown interest in testing for the presence of structural breaks in unemployment series. Papell et al. (2000) tested for a unit root (degree of integration 1) versus stationarity (degree of integration 0 ) in the presence of a structural break for 16 OECD countries. ${ }^{5}$ The choice is between $C(L) u_{t}=\epsilon_{t}$ and $C^{\prime}(L) u_{t}=\epsilon_{t}+\beta D_{t}$, where $C^{\prime}(L)$ is an invertible polynomial, $D_{t}$ is a dummy variable composed of zeros before the structural break and ones after the break. Of course, $D_{t}$ can be unique (single break) or multiple (multiple breaks). Papell et al. (2000) provide empirical evidence that is consistent with the structuralist theory, namely unemployment rate series are stationary around occasional structural breaks. ${ }^{6}$

Papell et al.'s (2000) results suggest that the natural rate of unemployment shifts over time. In the

\footnotetext{
${ }^{5}$ See also Arestis and Biefang (2000) for a similar analysis on 22 OECD countries but allowing for a single break only.

${ }^{6}$ Note that for the US, Papell et al. (2000) found two breaks: one in 1974 and the other in 1986.
} 
literature, various macroeconomic variables have been used to endogenize the natural rate of unemployment; Pissarides (1990) used the rate of productivity growth, Blanchard (1999) used real interest rates, Phelps (1999) used stock prices and Nickell (1998) and Nickell and Ours (2000) used summary indices of institutional variables embodied, for instance, in the level and duration of unemployment benefits, the degree of centralization of labor unions or labor taxation. Blanchard and Wolfers (2000) argued that the natural rate of unemployment is not primarily determined by macroeconomic or institutional variables directly but rather by their interaction. Institutions matter not because of their direct impact on unemployment but because they determine the sensitivity of unemployment to macroeconomic variables.

More recently, the debate has been revived by the development of the FARIMA (also called ARFIMA) fractional integration techniques that allow for a more general degree of persistence than the $0 / 1$ paradigm implied by unit root-tests, see Gil-Alana (2001) and Gil-Alana and Henry (2003) for instance. The aim in developing these techniques is to have a wide range of ARIMA models, which allow for fractional degrees of persistence. In this context, Equation 1 can be extended to:

$$
C^{*}(L)(1-L)^{d} u_{t}=w_{t}
$$

where $C^{*}(L)$ is an invertible polynomial such that $C(L)=C^{*}(L)(1-L)^{d}$, where $d$ may be a real value.

The process $w_{t}$ could itself be a stationary and invertible ARMA sequence, when its autocovariances decrease exponentially. However, their autocovariances could decrease much slower than exponentially. When $d=0, u_{t}=w_{t}$ and therefore $u_{t}$ is 'weakly autocorrelated', also called 'weakly dependent'. If $0<d<0.5, u_{t}$ is still stationary but its lagged $j$ autocovariance decreases very slowly, as the power law $j^{2 d-1}$ as $j \rightarrow \infty$ and so the autocovariances are non-summable. If $d$ increases such that it lies in the half open interval $\left[0.5,1\left[, u_{t}\right.\right.$ can be viewed as becoming 'more nonstationary' in the sense that the variance of the partial sums increases in magnitude. Because this also holds for $d>1$, a large class of nonstationary 
processes may be described with $d>0.5$. The distinction between $I(d)$ with different values of $d$ is also important for the hysteresis concept. If $d<1$, the process is mean-reverting, so while shocks do affect the system, the unemployment rate will return to its original level at some point in the future. While there is no hysteresis, the higher $d$, the longer the period of time necessary to return to the initial level. On the other hand, $d \geq 1$ means that unemployment is nonstationary and not mean-reverting, hence unemployment has hysteresis. A test for hysteresis thus consists of investigating the appropriate value of $d$.

This framework for testing the hypothesis of hysteresis can be extended in several ways. First, it can be used to distinguish between seasonal and long-run hysteresis. Most of the aforementioned studies used data which were filtered to remove seasonality. ${ }^{7}$ In doing so, the degree of long-run hysteresis is biased (see Candelon and Gil-Alana, 2004). Equation 1 must then be extended to:

$$
\left(1-L^{s}\right)^{d_{1}}(1-L)^{d_{2}} u_{t}=w_{t}
$$

where $s$ is equal to 12 for monthly data, $d_{1}$ refers to the order of integration at the seasonal frequencies, and $d_{2}$ is the order of integration at the long-run or zero frequency.

Note that the $w_{t}$ in Equation 2 allows us to include weak dependent autocorrelation, for example, the class of ARMA processes widely examined in the literature. The specification in the left hand side of equation 2 is fairly general and it permits us to consider several cases of interest, for example,

- $I(d)$ processes: In the case of $\rho(L ; d)=(1-L)^{d_{2}}$, or standard unit roots if $d_{2}=1$. This corresponds to the traditional hysteresis concept. Examples of applications of $\mathrm{I}(\mathrm{d})$ models in macroeconomics and finance are among others the paper of Diebold and Rudebush (1989), Baillie and Bollerslev (1994) and Gil-Alana and Robinson (1997).

\footnotetext{
${ }^{7}$ The most famous methods used to removed seasonality are the Holt-Winter, Census X12, Tramo-Seat and Band Pass Filters.
} 
- Seasonal $I(d)$ processes: $\rho(L ; d)=\left(1-L^{12}\right)^{d_{1}}$, or seasonal unit roots if $d_{1}=1$. In such a case unemployment would exhibit seasonal hysteresis. Seasonal I(d) models have been examined by PorterHudack (1990), Hassler (1994), Arteche and Robinson (2000) and more recently, Gil-Alana (2002).

Second, the framework can be extended to allow the investigation of the structuralist theory. If the degrees of persistence are modified after the inclusion of a break, this would provide some support for both the structuralist and the hysteresis schools, i.e. macroeconomic shocks have persistent though not permanent effects on the unemployment rate, as argued by the hysteresis school, and macroeconomic structure may have persistent effects on the natural rate of unemployment, as predicted by the structuralists. It is usually assumed that the date of the structural break (if the break exists) is known. ${ }^{8}$ We drop this assumption and consider the potential existence of a structural break at an unknown date in a fractional integrated framework.

\section{Seasonal and Long-Run Fractional Integration in the Presence of a Structural Break at an Unknown Date}

Suppose that $u_{t}$ is an observable time series, not adjusted for seasonality, i.e. the occupational unemployment rate in our case, and that is driven by the regression model:

$$
u_{t}=\beta^{\prime} z_{t}+x_{t}, \quad t=1, . . T
$$

where $z_{t}$ is a $(k \times 1)$ vector of non-stochastic elements and $\beta$ is a $(k \times 1)$ vector of unknown parameters.

In Robinson (1994), the $x_{t}$ are driven by the model:

\footnotetext{
${ }^{8}$ For example, Gil-Alana (2002) in his post WWII data, considers a break occurring in the third quarter of 1973
} 


$$
\rho(L ; d) x_{t}=w_{t}, \quad t=1, . . T
$$

where $w_{t}$ is an $\mathrm{I}(0)$ process, defined for the purpose of the present work, as a covariance stationary process, with spectral density function that is bounded and bounded away from zero at any frequency on the spectrum.

The function $\rho$ is a complicated function, which may include single or multiple roots in the unit circle at various frequencies in the spectrum. For the purpose of our paper, we suppose that is given by:

$$
\rho(L ; d)=\left(1-L^{12}\right)^{d_{1}}(1-L)^{d_{2}} .
$$

Robinson (1994) proposed a Lagrange Multiplier (LM) test of the null hypothesis:

$$
H_{0}: d \equiv\left(d_{1}, d_{2}\right)^{\prime}=\left(d_{1,0}, d_{2,0}\right)^{\prime} \equiv d_{0},
$$

in the model given by equations $(3)-(5)$. We denote this test statistic $\widehat{R}$ in the rest of the paper. ${ }^{9}$

Based on $H_{0}$ (Equation 6), Robinson (1994) established that, under certain regularity conditions, ${ }^{10}$ the test statistic $\hat{R}$ follows asymptotically a $\chi^{2}(2)$ distribution. Thus, as shown by Robinson (1994) and unlike other procedures, we are in a classical large-sample testing situation. A test of (6) will reject $H_{0}$ against the alternative $H_{a}: d \neq d_{0}$ if $\hat{R}>\chi_{2, \alpha}^{2}$, where $\operatorname{Prob}\left(\chi_{2}^{2}>\chi_{2, \alpha}^{2}\right)=\alpha$. Furthermore, the test is efficient in the Pitman sense against local departures from the null, in the sense that if the test is implemented against local departures of form: $H_{a}: d=d_{0}+\delta T^{-1 / 2}$, for $\delta \neq 0$, the limit distribution is a $\chi_{2}^{2}(v)$ with a non-centrality

\footnotetext{
${ }^{9}$ The description of this test statistic is available on a web appendix at http://www.roa.unimaas.nl/cv/Dupuy/Dupuy.htm or from the authors upon request.

10 These conditions are very mild and concern technical assumptions to be satisfied by the model in (3) - (5).
} 
parameter $v$, which is optimal under Gaussianity of $w_{t}$.

This test can be particularized to analyze the presence of a structural break. We therefore suppose that $z_{t}$ in equation 3 contains dummy variables for the breaks. For simplicity, we only consider the cases of a level shift, i.e. $z_{t}=L_{t}=I\left(t>T_{b}\right)$, and a slope change $\left(z_{t}=S_{t}=\left(t-T_{b}\right) I\left(t>T_{b}\right)\right)$, though other more elaborated models can also be considered. In what follows, we assume that the time of the break $\left(T_{b}\right)$ is unknown so that it will be implicitly determined by the procedure. The testing procedure is simple. We start by computing the test of Robinson (1994) as previously described, testing $H_{0}$ (Equation 6) for different values of $d_{0}$, recursively, assuming that there is a break at time $T_{b}=2, \ldots, T-1$. Then, we collect the values of $d_{0}$ where $H_{0}$ cannot be rejected only for the cases where the coefficient for the dummy is statistically different from zero. In other words, we test $H_{0}(6)$, in the model given by:

$$
u_{t}=\beta D_{t}+x_{t}, \quad \rho(L ; d) x_{t}=w_{t}, \quad \rho(L ; d)=\left(1-L^{12}\right)^{d_{1}}(1-L)^{d_{2}}
$$

conditioned to $\beta \neq 0$.

Once the possible $d_{0}$ 's are selected, (i.e. those where $H_{0}$ cannot be rejected and the dummy coefficient is statistically significant), we retain the pair $\left(d_{10}, d_{20}\right)$ for which the $t$-statistics associated to $\beta$ is the highest. The asymptotic behavior of this procedure is expected to be standard normal ${ }^{11}$ though, since it is based on model selection, that should affect statistical inference (see Leeb and Pötscher, 2005). The interpretation of the break is not straightforward as it refers to both the seasonal and the long-run persistence. It nevertheless indicates a structural change in the labor market behavior.

\footnotetext{
${ }^{11}$ The derivation of the asymptotic properties of the test as well as a Monte Carlo simulation study of the small sample properties of the test are available on a web appendix at http://www.roa.unimaas.nl/cv/Dupuy/Dupuy.htm or from the authors upon request.
} 


\section{Empirical application}

\subsection{Data}

We use monthly times series of unemployment rate by occupation for the time period January 1982 to December 2002. These series are obtained from the Current Population Survey (CPS), a survey of households conducted monthly by the U.S. Department of Labor, Bureau of Labor Statistics (BLS).

In this paper, we are mainly interested in the relationship between unemployment rates and skills. Ideally we would observe an individual's skills and then would be able to derive time series of unemployment rates by level and type of skills. However, in practice, individuals' skills are unobserved and have to be approximated. The proxies most often used in the labor economics literature are education (years of schooling) and occupations. In fact, studies investigating the effect of skills on earnings have used both proxies and found that both education and occupation explain about the same share of earnings differentials between individuals. In this paper, however, we need a fairly large number of observations in order to be able to estimate fractional densities for each series. Whereas monthly data by educational levels (college, less than bachelor, high school and less than high school graduates) are available for the period January 1992 to February 2005 offering 158 observations, the monthly occupational unemployment series cover 20 years of observations, i.e. 240 observations per occupation. The skill proxy "occupation" offers many more degrees of freedom with which to estimate the demanding fractional density of the series, which motivates our choice in favor of the occupational series. Note moreover that the occupational series are available at a rather low level of aggregation, which enables us to infer not only on an individual's skills level (occupational level) but also on her type of skills (types of occupation).

Occupational unemployment series are derived as follows. The BLS counts as unemployed, in an occupation say $A$, every person classified as unemployed for whom the last job before becoming unemployed was a job in occupation $A$. The access to this information is possible since in the CPS individuals are asked what 
their last occupation was before becoming unemployed.

\subsection{Results}

Three experiments are performed on each of the occupational unemployment series. First, a test for long-run fractional integration in the presence of a structural break at an unknown date is performed, neglecting to adjust the data for seasonality. This may correspond to the case of an unwise applied econometrician, who ignores seasonality. In the second experiment, the data are seasonally adjusted using the Holt-Winter filter 12 and a test for long-run fractional integration is performed in the presence of a structural break at an unknown break date. Such an experiment corresponds to what is traditionally done in empirical studies. Finally, we test for seasonal and long-run fractional integration as presented in the previous section. ${ }^{13}$

Results of the estimation for the 49 different occupations are presented in Tables $5-8$ according to the different sectors of activity. Several results can be drawn.

1. Estimating the long-run degree of fractional integration on the data non-adjusted for seasonality, reveals that persistence in low-skill occupations is higher than in high-skill occupations. Lawyers and judges (sector 21), natural scientists (sector 28), supervisors (sector 43) farm operator managers (sector 10) or sales related employees (sector 40) have a degree of fractional integration four times lower than the secretary (sector 41) or the farm-related occupations (sector 11). This indicates that a negative shock affecting a high skill sector will disappear in the long run, whereas it will persist in low skill sectors. This result could be explained by the fact that low skilled workers are backward looking (adaptative expectations) whereas skilled workers tend to be forward looking (near rational) expectations. Another explanation could be that firms hoard skilled labor during adverse shocks, and possibly train them in

\footnotetext{
${ }^{12}$ Herewith seasonality is removed using the multiplicative Holt-Winter method. Similar results have been found using different methods to remove seasonality. Results are available from the authors upon request.

${ }^{13}$ Seasonal dummy variables can also be included in the regression model (8), though its inclusion would imply that at least part of the seasonality has a deterministic component. In this article, however, we believe that the seasonal component in the unemployment rates is purely stochastic, which may be stationary $\left(d_{1}<0.5\right)$ or nonstationary $\left(d_{1}>0.5\right)$
} 
this idle period, whereas unskilled workers are laid off and possibly loose part of their skills while being unemployed, which makes them less attractive for firms to hire when the economy gets back on its long run path. Note that this difference in persistence is not found in the case of the break date. Almost all series admit a break (except the administrative support (sector 1)) in first half of the 90s. This supports the structuralist view.

2. Considering now the data purged of seasonality by using the Holt-Winter filter, we notice that the long run persistence increases for almost all series, converging toward unity. The presence of a break date in the early nineties is also confirmed. These results are in line with previous studies which have stressed the hysteresis of unemployment data.

3. In the third experiment, we estimate the degree of persistence of seasonal shocks together with the degree of long-run persistence without applying any seasonal filter. It turns out that for almost all series, the degree of long-run fractional integration is larger than 1, indicating long run hysteresis. A remarkable result is that the degree of long run persistence obtained, when jointly estimating both the long run and the seasonal cases is much higher than when estimating this value with series that are seasonally adjusted with traditional filters. This indicates that long run hysteresis has been systematically underestimated in previous empirical studies that use seasonally adjusted series.

Our study clearly indicates that the hysteresis and the structuralist schools can live together and both are useful for understanding unemployment dynamics. Nevertheless, it reveals the importance of the treatment of seasonality. The magnitude of the degree of persistence in occupational unemployment series estimated in this paper casts some doubt on previous analyses that exhibit hysteresis in unemployment series based on seasonally adjusted data. Moreover, our results call for a new theory that is able to explain the mechanism by which this tremendous hysteresis emerges. The traditional explanation of long run hysteresis (see Blanchard and Summers (1986)) rests on three pillars: i) physical capital, ii) human capital and iii) insider-outsider 
model. The physical capital stories state that reductions in the stock of capital following the reduction of employment due to a adverse shock subsequently reduces labor demand and so on. The human capital hypothesis states that workers, when unemployed, loose opportunities to maintain or even increase their skills which reduces the effective supply of labor. The third hypothesis by which hysteresis could emerge is the insider-outsider model developed by Lindbeck and Snower (1986). Following an adverse shock, employment reduces so that the insiders form a smaller group which enables them to set a new wage so as to maintain a new lower employment level. Unemployment follows a random walk and is therefore solely determined by the history of shocks. None of these stories provide a satisfactory explanation for hysteresis of the magnitude estimated in this paper. This empirical study calls for theoretical microeconomic models that are able to account for the high persistence (more persistence than in the insider outsider model (random walk)) of shocks in unemployment series.

\section{Conclusions}

In this paper, we have taken a deeper look at the debate between structuralist and hysteresis hypotheses. To this aim, we have built a new approach for estimating seasonal and long run fractional integration in the presence of a break at an unknown date. Fractional integration allows us to investigate a broader range of persistence or memory than the $0 / 1$ paradigm most notably implemented in studies of unemployment patterns (see Blanchard and Summers (1986), Barro (1988) and Alogoskoufis and Manning (1988)) and recently adapted to test for stochastic nonstationarity versus deterministic seasonality (see Hylleberg et al (1990) and Beaulieu and Miron (1993)) as well as to distinguish between seasonal and long-run hysteresis.

Using non-seasonally adjusted unemployment rates for different occupations in the US, we tested for the presence of seasonal and long run persistence in the presence of a structural break at an unknown date. For each occupation, we perform three experiments on the unemployment series. First, a test for long-run 
fractional integration in the presence of a structural break at an unknown date is performed without adjusting the data for seasonality. Second, a similar test using seasonally adjusted data is performed. Third, a test for seasonal and long-run fractional integration on raw data is carried out. This enables us to investigate not only i) the long run persistence of shocks in the unemployment series (traditional hysteresis hypothesis, Blanchard and Summers (1986;1987) and Cross (1987)) and ii) the presence of structural breaks of unknown timing (structuralist hypothesis, Phelps (1994)), but also iii) the seasonal persistence of shocks (seasonal hysteresis).

The empirical results reported in this paper support the structuralist hypothesis as a structural break is found in the early $90 \mathrm{~s}$ in all our experiments. The hysteresis hypothesis is also supported and the degree of persistence estimated in this paper is for almost all series larger than 1. Our results cast some doubt on previous analyses that exhibit hysteresis in unemployment series based on seasonally adjusted data. Moreover, these results call for a new theory that is able to explain the mechanism by which hysteresis of the magnitude reported in this paper can emerge.

\section{References}

Abeysinghe, T. (1994): "Deterministic Seasonal Models and Spurious Regressions," Journal of Econometrics, 61, 259-72.

Alogoskoufis, G., and A. Manning (1988): "Wage Setting and Unemployment Persistence in Europe, Japan and the USA," European Economic Review, 32(1), 698-706.

Andrews, D. (1993): "Tests for Parameter Instability and Structural Change with Unknown Change Point," Econometrica, 61(4), 821-56.

Arestis, P., and I. Biefang-Frisancho Mariscal (2000): "OeCD Unemployment: Structural Breaks and Stationarity," Applied Economics, 32(4), 399-403. 
BARro, R. (1988): "The Natural Rate Theory Reconsidered: The Persistence of Unemployment," American Economic Review, Papers and Proceedings, 78, 32-7.

Beaulieu, J., And J. A. Miron (1993): "Seasonal Unit Roots in Aggregate US Data," Journal of Econometrics, 55, 305-28.

Blanchard, O., And L. Katz (1999): "Wage Dynamics: Reconciling Theory and Evidence," American Economic Review, Papers and Proceedings, 89(2), 69-74.

Blanchard, O., and L. Summers (1986): "Hysteresis and the European Unemployment Problem," NBER Working Paper Series, 1950.

(1987): "Hysteresis in Umemployment," European Economic Review, 31(1), 288-95.

Blanchard, O., and J. Wolfers (2000): "The Role of Shocks and Institutions in the Rise of European Unemployment: The Aggregate Evidence," Economic Journal, 110(462), C1-33.

Clark, K., and L. Summers (1981): "Demographic Differences in Cyclical Employment Variation," Journal of Human Resources, 16(1), 61-79.

Cross, R. (1987): "Hysteresis and Instability in the Natural Rate of Unemployment," Scandinavian Journal of Economics, 89(1), 71-89.

Devereux, P. (2002): "Occupational Upgrading and the Business Cycle," Labour, 16(3), 423-52.

Dickey, D., And W. Fuller (1979): "Distributions of the Estimators for Autoregressive Time Series with a Unit Root," Journal of the American Statistical Association, 74, 427-31.

Diebold, F. X., And G. D. Rudebusch (1991): "On the Power of Dickey-Fuller Tests Against Fractional Alternatives," Economics Letters, 35(2), 155-160. 
Fabiani, S., A. Locarno, G. P. Oneto, and P. Sestito (2001): "The Sources of Unemployment Fluctuations: An Empirical Application to the Italian Case," Labour Economics, 8(2), 259-89.

Friedman, M. (1968): "The Role of Monetary Policy," American Economic Review, 58(1), 1-17.

Ghysels, E. (1994): "On the Periodic Structure of the Business Cycle," Journal of Business and Economic Statistics, 12(3), 289-98.

Gil-Alana, L. (2001): "The Peristence of Unemployment in the USA and Europe in Terms of Fractional ARIMA Models," Applied Economics, 33(10), 1263-1269.

(2002): "Structural Breaks and Fractional Integration in the US Output and Unemployment Rate," Economics Letters, 77(1), 79-84.

Gil-Alana, L., And B. Henry (2003): "Fractional Integration and the Dynamics of UK Unemployment," Oxford Bulletin of Economics and Statistics, 65(2), 221-39.

Hassler, U., And J. Wolters (1994): "On the Power of Unit Root Tests Against Fractional Alternatives," Economics Letters, 45, 1-5.

Hylleberg, S., R. Engle, C. Granger, and B. Yoo (1990): "Seasonal Integration and Cointegration," Journal of Econometrics, 44, 215-38.

Lindbeck, A., And D. J. Snower (1986): "Wage Setting, Unemployment, and Insider-Outsider Relations," American Economic Review, 76(2), 235-39.

Miron, J. A. (1990): "The Economics of Seasonal Cycles," NBER Working Paper, 3522.

Miron, J. A., And J. J. Beaulieu (1996): "What Have Macroeconomists Learned About Business Cycles from the Study of Seasonal Cycles?," Review of Economics and Statistics, 78, 54-66. 
Mitchell, W. F. (1993): "Testing Unit Roots and Persistence in OECD Unemployment," Applied Economics, 25, 1489-1501.

Nickell, S. (1998): "Unemployment: Questions and Some Answers," Economic Journal, 108(448), 802-16.

Nickell, S., And J. Van Ours (2000): "The Netherlands and the United Kingdom: A European Unemployment Miracle?," Economic Policy, 30, 135-80.

Okun, A. (1962): "Potential GNP: Its Measurment and Significance," in Proceedings of the Business and Economics Statistics Section. American Statistical Association, Washington DC.

Papell, D., C. Murray, and H. Ghiblawi (2000): "The Structure of Unemployment," Review of Economics and Statistics, 82(2), 309-15.

Phelps, E. (1967): "Philips Curves, Expectations of Inflation and Optimal Unemployment over Time," Economica, 34(135), 254-81.

(1968): "Money, Wage Dynamics and Labor Market Equilibrium," Journal of Political Economy, $76(4), 678-711$.

(1994): Structural Slumps: The Modern Equilibrium Theory of Unemployment, Interest, and Assets.

Cambridge, MA: Harvard University Press.

(1999): "Behind This Structural Boom: The Role of Asset Valuations," American Economic Review, Papers and Proceedings, 89(2), 63-8.

Phillips, P. C., And P. Perron (1988): "Testing for Unit Root in a Time Series Regression," Biometrika, $75,335-46$.

Pissarides, C. (1990): Equilibrium Unemployment Theory. Oxford: Basil Blackwell. 
RAY, R. (1976): "Dispersion Tendencies in Occupational Unemployment Rates," Monthly Labor Review, $99(4), 38-41$.

Robinson, P. M. (1994): "Efficient Tests of Nonstationarity Hypothesis," Journal of the American Statistical Association, 89(428), 1420-37.

Teulings, C., and M. Koopmanschap (1989): "An Econometric Model of Crowding Out of Lower Education Levels," European Economic Review, 33(8), 1653-64.

Thurow, L. (1965): "The Changing Structure of Unemployment: An Econometric Study," Review of Economics and Statistics, 47(2), 137-49.

Tolvi, J. (2003): "Unemployment Persistance of Different Labour Force Groups in Finland," Applied Economics Letters, 10(8), 455-458.

(Van) Dijck, D., B. Strikholm, and T. Teräsvirta (2003): "The Effects of Institutional and Technological Change and Business Cycle Fluctuations on Seasonal Patterns in Quarterly Industrial Production Series," Econometrics Journal, 6, 79-98.

Vedder, R., and L. Gallaway (1992): "Racial Differences in Unemployment in the United Sates, 18901990," Journal of Economic History, 52(3), 696-702.

Wen, Y. (2002): "The Business Cycle Effects of Christmas," Journal of Monetary Economics, 49, 1289-314. 
Table 1: Degree of integration, d, and structural break by occupational sector and level.

\begin{tabular}{|c|c|c|c|c|c|c|c|c|c|c|}
\hline \multirow[b]{2}{*}{ Occupations } & \multicolumn{3}{|c|}{ Seasonally non adjusted } & \multicolumn{3}{|c|}{ Seasonally adjusted $^{1}$} & \multicolumn{4}{|c|}{ Seasonally non adjusted } \\
\hline & $\begin{array}{r}\text { Long run } \\
d_{2}\end{array}$ & $\begin{array}{r}\text { Break } \\
\text { Date }\end{array}$ & T-test & $\begin{array}{r}\text { Long run } \\
d_{2}\end{array}$ & $\begin{array}{l}\text { Break } \\
\text { Date }\end{array}$ & T-test & $\begin{array}{l}\text { Long run } \\
d_{2}\end{array}$ & $\begin{array}{l}\text { Short run } \\
d_{1}\end{array}$ & $\begin{array}{l}\text { Break } \\
\text { Date }\end{array}$ & T-test \\
\hline Health & & & & & & & & & & \\
\hline 18 Diagnosing & 0.3 & & & 0.4 & 92:09 & -1.698 & 1.8 & 0.5 & $96: 08$ & -2.159 \\
\hline 17 Assessment & 0.5 & $96: \overline{11}$ & $-1.66 \overline{8}$ & 0.8 & $96: 10$ & -1.654 & 1.8 & 0.5 & $96: 03$ & 2.703 \\
\hline 20 Technician & 0.7 & $96: 01$ & 2.212 & 0.9 & 92:08 & 2.396 & 0.8 & 1.8 & 95:04 & 3.269 \\
\hline $\begin{array}{l}19 \text { Service } \\
\text { Teaching }\end{array}$ & 0.8 & $94: 01$ & 2.291 & 1.0 & 93:08 & 1.662 & 1.2 & 0.4 & $94: 01$ & 2.150 \\
\hline 44 College/University & 0.8 & $94: 06$ & 3.860 & 1.1 & $96: 06$ & 2.467 & 1.8 & 0.6 & $96: 07$ & 4.444 \\
\hline $\begin{array}{l}45 \text { Other } \\
\text { Law }\end{array}$ & 1.2 & $95: 06$ & 3.748 & 1.3 & 96:09 & -3.125 & 1.8 & 1.8 & $96: 08$ & -2.070 \\
\hline 21 Lawyers and Judges & 0.4 & $95: 11$ & -1.840 & 0.5 & $96: 10$ & -1.818 & 0.4 & 0.5 & $96: 11$ & 2.490 \\
\hline
\end{tabular}

${ }^{1}$ Series adjusted for seasonality using Holt-Winter seasonal exponential smoothing 
Table 2: Degree of integration, d, and structural break by occupational sector and level.

\begin{tabular}{|c|c|c|c|c|c|c|c|c|c|c|}
\hline \multirow[b]{2}{*}{ Occupations } & \multicolumn{3}{|c|}{ Seasonally non adjusted } & \multicolumn{3}{|c|}{ Seasonally adjusted $^{1}$} & \multicolumn{4}{|c|}{ Seasonally non adjusted } \\
\hline & $\begin{array}{r}\text { Long run } \\
d_{2}\end{array}$ & $\begin{array}{r}\text { Break } \\
\text { Date }\end{array}$ & T-test & $\begin{array}{l}\text { Long run } \\
d_{2}\end{array}$ & $\begin{array}{l}\text { Break } \\
\text { Date }\end{array}$ & T-test & $\begin{array}{l}\text { Long run } \\
d_{2}\end{array}$ & $\begin{array}{l}\text { Short run } \\
d_{1}\end{array}$ & $\begin{array}{l}\text { Break } \\
\text { Date }\end{array}$ & T-test \\
\hline Management & & & & & & & & & & \\
\hline 24 Management & 0.7 & $94: 04$ & -1.707 & 1.0 & 94:01 & 2.049 & 1.7 & 0.5 & $93: 10$ & -1.695 \\
\hline 13 Financial processing & 0.6 & $96: 08$ & -1.675 & 0.9 & $95: 04$ & -1.642 & 1.5 & 0.5 & $96: 03$ & 2.994 \\
\hline 25 Managerial/professionals & 1.0 & $94: 06$ & 2.124 & 1.1 & $94: 07$ & 2.093 & 1.1 & 0.4 & 94:06 & 2.046 \\
\hline 34 Professional specialty & 1.0 & $94: 06$ & 3.162 & 1.1 & $94: 07$ & 2.572 & 1.8 & 0.4 & 94:06 & 2.391 \\
\hline 8 Executive administrative & 0.9 & 91:01 & 2.233 & 1.0 & $92: 01$ & 2.225 & 0.6 & 0.4 & 91:01 & 2.245 \\
\hline 31 Other executive & 0.8 & $94: 05$ & -1.946 & 1.0 & 93:01 & 2.499 & 0.5 & 0.4 & 91:01 & 2.554 \\
\hline 41 Secretary/stenographer & 1.5 & $89: 10$ & 25.255 & 1.0 & $92: 01$ & 1.656 & 1.2 & 0.4 & $89: 10$ & 10.433 \\
\hline 1 Administrative support & 0.9 & & & 1.0 & $92: 01$ & 1.834 & 1.8 & 0.4 & $96: 07$ & 1.735 \\
\hline $\begin{array}{l}23 \text { Mail-Message distributing } \\
\text { Services }\end{array}$ & 0.4 & $96: \overline{12}$ & $-1.8 \overline{15}$ & 0.7 & $95: 12$ & -1.786 & 1.8 & 0.4 & $96: 07$ & 2.831 \\
\hline 35 Protective & 0.7 & $96: 08$ & -1.947 & 0.9 & $92: 05$ & 1.798 & 1.1 & 0.4 & $92: 04$ & 3.23 \\
\hline 32 Personal & 0.8 & $95: 06$ & 2.187 & 1.0 & $91: 06$ & 1.812 & 0.8 & 0.4 & $96: 06$ & -1.782 \\
\hline 14 Food & 0.9 & 93:01 & 2.210 & 1.0 & & & 1.1 & 0.4 & $96: 12$ & -1.768 \\
\hline 16 Handlers equipment/cleaning & 1.0 & 94:01 & 2.859 & 1.1 & $\overline{92}: 01$ & $\overline{1} .925$ & 1.8 & 0.4 & $96: 06$ & -1.820 \\
\hline 2 Cleaning building & 0.7 & $96: 02$ & -1.776 & 0.9 & - & - & 1.6 & 0.4 & 94:01 & 2.616 \\
\hline 42 Services Occupations & 1.0 & 94:01 & 2.883 & 1.0 & & - & 1.6 & 0.4 & $93: 12$ & -1.748 \\
\hline
\end{tabular}

${ }^{1}$ Series adjusted for seasonality using Holt-Winter seasonal exponential smoothing 
Table 3: Degree of integration, d, and structural break by occupational sector and level.

\begin{tabular}{|c|c|c|c|c|c|c|c|c|c|c|}
\hline \multirow[b]{2}{*}{ Occupations } & \multicolumn{3}{|c|}{ Seasonally non adjusted } & \multicolumn{3}{|c|}{ Seasonally adjusted $^{1}$} & \multicolumn{3}{|c|}{ Seasonally non adjusted } & \multirow[b]{2}{*}{ T-test } \\
\hline & $\begin{array}{l}\text { Long run } \\
d_{2}\end{array}$ & $\begin{array}{r}\text { Break } \\
\text { Date }\end{array}$ & T-test & $\begin{array}{r}\text { Long run } \\
d_{2}\end{array}$ & $\begin{array}{l}\text { Break } \\
\text { Date }\end{array}$ & T-test & $\begin{array}{r}\text { Long run } \\
d_{2}\end{array}$ & $\begin{array}{r}\text { Short run } \\
d_{1}\end{array}$ & $\begin{array}{l}\text { Break } \\
\text { Date }\end{array}$ & \\
\hline $\begin{array}{l}28 \text { Natural Scientists } \\
\text { Engineering }\end{array}$ & 0.4 & $96: 10$ & -1.801 & 0.7 & $96: 01$ & -1.842 & 0.4 & 0.5 & $95: 10$ & -1.673 \\
\hline 43 Supervisors & 0.4 & $95: 03$ & -2.122 & 1.0 & $93: 05$ & 2.375 & 0.4 & 0.5 & $94: 10$ & -1.685 \\
\hline 3 Computer equipment operator & 0.5 & $96: 10$ & -1.894 & 0.8 & $93: 05$ & 2.647 & 1.1 & 0.4 & $96: 11$ & 2.351 \\
\hline 6 Engineers science technicians & 0.7 & $96: 12$ & -1.877 & 0.9 & 93:01 & 2.444 & 1.8 & 0.4 & 92:09 & 2.916 \\
\hline 7 Engineers & 0.8 & 96:08 & -1.654 & 0.8 & $92: 01$ & 2.772 & 0.4 & 1.8 & 92:01 & 2.521 \\
\hline 33 Precision prod., craft repair & 1.0 & 92:01 & 2.675 & 1.2 & 94:01 & 2.341 & 1.8 & 0.4 & $93: 11$ & -1.655 \\
\hline 9 Fabricators, Assemblers & & & & 0.9 & 91:01 & 1.898 & 1.8 & 0.4 & 90:02 & -1.962 \\
\hline 22 Machine operators & 0.8 & $94: 05$ & -1.646 & 1.0 & & & 1.1 & 0.4 & & \\
\hline 26 Mechanic repairers & 0.9 & 92:01 & 2.338 & 1.1 & $\overline{93}: 01$ & $\overline{1.837}$ & 1.6 & 0.4 & $96: \overline{10}$ & $-1.8 \overline{8}$ \\
\hline 27 Motor vehicle operators & 0.9 & 90:01 & 2.329 & 1.1 & $92: 01$ & 2.437 & 1.8 & 0.4 & $96: 11$ & -1.737 \\
\hline 29 Fabricators and laborers & 1.1 & 94:01 & 1.788 & 1.1 & $92: 01$ & 2.014 & 1.8 & 0.4 & 90:02 & -1.737 \\
\hline 30 Operators tenders & 0.8 & $94: 05$ & -1.739 & 1.0 & & & 0.3 & 0.3 & & \\
\hline 48 Technicians (excl. health) & 0.6 & $96: 04$ & -2.199 & 1.0 & $\overline{92}: 06$ & $\overline{2.261}$ & 1.4 & 0.4 & $96: \overline{10}$ & $-2.23 \overline{1}$ \\
\hline 49 Other Technicians & 0.8 & 96:04 & -1.712 & 0.8 & 94:03 & -1.772 & 1.2 & 0.5 & 93:06 & 3.143 \\
\hline
\end{tabular}


Table 4: Degree of integration, d, and structural break by occupational sector and level.

\begin{tabular}{|c|c|c|c|c|c|c|c|c|c|c|}
\hline \multirow[b]{2}{*}{ Occupations } & \multicolumn{3}{|c|}{ "Seasonally non adjusted } & \multicolumn{3}{|c|}{ Seasonally adjusted ${ }^{1}$} & \multicolumn{3}{|c|}{ Seasonally non adjusted } & \multirow[b]{2}{*}{ T-test } \\
\hline & $\begin{array}{r}\text { Long run } \\
d_{2}\end{array}$ & $\begin{array}{r}\text { Break } \\
\text { Date }\end{array}$ & T-test & $\begin{array}{r}\text { Long run } \\
d_{2}\end{array}$ & $\begin{array}{l}\text { Break } \\
\text { Date }\end{array}$ & T-test & $\begin{array}{r}\text { Long run } \\
d_{2}\end{array}$ & $\begin{array}{r}\text { Short run } \\
d_{1}\end{array}$ & $\begin{array}{l}\text { Break } \\
\text { Date }\end{array}$ & \\
\hline Construction & & & & & & & & & & \\
\hline 5 Traders & 1.0 & 92:01 & 2.791 & 1.0 & 92:01 & 2.516 & 1.8 & 0.4 & $92: 04$ & -1.891 \\
\hline $\begin{array}{l}4 \text { Laborers } \\
\text { Sales }\end{array}$ & 1.1 & 94:01 & 2.035 & 1.2 & $92: 01$ & 2.125 & 1.6 & 0.4 & $96: 12$ & -2.439 \\
\hline 37 Finance and Business & 0.6 & $96: 12$ & -1.800 & 0.7 & $95: 10$ & -1.807 & 1.0 & 0.4 & $96: 12$ & -3.054 \\
\hline 36 Representatives commodities & 0.5 & $96: 12$ & -1.679 & 1.0 & 89:01 & 2.996 & 0.8 & 0.4 & $96: 12$ & -2.127 \\
\hline 38 Retails personal & 0.9 & 96:01 & 2.727 & 0.9 & 94:01 & 2.159 & 1.8 & 0.4 & $95: 10$ & -2.078 \\
\hline 46 Tech. administration support & 0.9 & - & - & 1.0 & 92:01 & 2.137 & 1.1 & 0.4 & - & - \\
\hline 47 Tech. administrative support & 1.0 & & & 1.1 & & & 0.3 & 0.3 & & \\
\hline 39 Sales occupations & 0.9 & $96: 0 \overline{1}$ & $2.19 \overline{5}$ & 1.0 & $\overline{92}: 01$ & $\overline{2} .267$ & 1.6 & 0.4 & $93: \overline{02}$ & $-1.75 \overline{5}$ \\
\hline $\begin{array}{l}40 \text { Sales related } \\
\text { Farm }\end{array}$ & 0.3 & - & - & 0.4 & $96: 05$ & -2.023 & 1.8 & 0.5 & 94:01 & 4.575 \\
\hline 10 Farm_operators_managers & 0.3 & & & 1.0 & $96: 12$ & 1.828 & 0.7 & 0.4 & $91: 12$ & 2.043 \\
\hline 11 Farm_related occupations & 1.3 & $95: \overline{04}$ & $-1.79 \overline{9}$ & 1.2 & $96: 04$ & -1.706 & 1.8 & 0.4 & $94: 04$ & -2.136 \\
\hline 12 Farming Forestry Fishing & 1.3 & $94: 07$ & 1.683 & 1.4 & $96: 04$ & -1.701 & 1.8 & 0.5 & $94: 04$ & -1.649 \\
\hline 15 Forestry Fishing occupations & 0.7 & 96:01 & 3.789 & 1.2 & $95: 01$ & 2.427 & 0.4 & 1.7 & $96: 01$ & 3.777 \\
\hline
\end{tabular}

${ }^{1}$ Series adjusted for seasonality using Holt-Winter seasonal exponential smoothing 